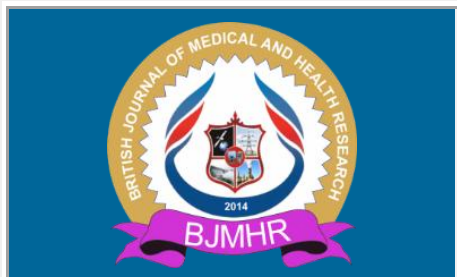

\title{
BJMHR
}

British Journal of Medical and Health Research Journal home page: www.bjmhr.com

\section{Medical Undergraduates Preference in Learning Style: Power Point Presentations Versus Chalk and Talk}

\author{
Anil Kumar ${ }^{1}$, Nasser Salem Al-Nazwani ${ }^{2}$, Shivaraj Gowda ${ }^{\mathbf{3}}$ \\ 1.College of Medicine and Health Science, National University of Science and Technology \\ Sohar, Al tareef, Postal code: 391, P. O. Box: 321 Sultanate of Oman
}

\section{ABSTRACT}

Learning style preferences are the manner and conditions under which learners most efficiently and effectively perceive process, store, and recall what they are attempting to learn. Lectures have been the most common form of teaching and learning since ancient times. The most common ways of lecture delivery include the lectures using PowerPoint (PPT) presentations, lectures utilizing the transparency and overhead projector (TOHP) besides the traditional 'chalk and talk' method. Didactic lectures are still the most commonly used methodology of teaching. The objective of the study is to compare PowerPoint presentations versus chalk and talk in material understanding, effectiveness and attitude among medical students. A cross sectional questionnaire based study was conducted on $3^{\text {rd }}$ year medical students of College of Medicine and Health Science, NUST, Sohar. The study participant was divided into two groups. The first groups of students were taught on the black board (chalk and talk) and the second groups of students were taught on PPT presentation. The same biochemistry topics were taught to both groups by the same instructor and on the scheduled time and day. A questionnaire was designed to assess the opinion of students regarding black board and PPT presentation. A predesigned and pretested questionnaire containing 12 questions was given to the students at the end of the lecture. The participation in the present study was on voluntary basis. In this study, PPT teaching was the most preferred teaching aid (60.23\%) compared to black board teaching method (46.38\%). Majority of the students reported well prepared and organized lectures, more subject coverage, and better demonstrations of clinical conditions is seen in PPT teaching then black board teaching. PPT presentation teaching is the best preferred teaching aid, which can be supplemented by Blackboard for better understanding.

Keywords: Lectures, PowerPoint, Presentations, Chalk and talk, Black board, Didactic lectures 


\section{INTRODUCTION}

Teaching and learning are active and continuous processes. Teaching is an art of facilitating and supporting learning character in students. However, learning is a cognitive process whereby an individual acquires the professional and ethical values, the biomedical, behavioral and clinical knowledge, reasoning and psychomotor skills necessary for professional competence. Lectures have been the most common form of teaching and learning since ancient times. Didactic lecture is more passive in nature and less effective teaching tool when compared with active learning such as problem based learning and bedside teaching (in medical field). However, a well organized lecture remains one of the most effective ways to integrate and present information from multiple sources ${ }^{1-2}$.

Traditional lectures on blackboard or "chalk and talk" is commonly used in lectures as a mode of delivering information, while the use of transparencies and PowerPoint (PPT) with an overhead projector (OHP) is the other effective modes of delivering lectures in modern era. Since last few years, technological advancements have revolutionized in every field including teaching. Use of electronic presentations has become very frequent, and Microsoft PowerPoint is now the most popular teaching aid used out of all electronic presentations even in medical education $^{3-4}$.

Various studies have been conducted to know the best method from these available teaching methods and some of these studies have even ended inconclusively. So, in a view to modify our teaching methodology, we conduct this study to evaluate the effectiveness of currently used teaching methods in classes for the medical undergraduate students. This study is to compare the role and effectiveness of lecture delivery using black board versus PowerPoint presentation in material understanding, effectiveness and attitude among the students perception of College of Medicine and Health Sciences, National University of Science and Technology (NUST), Sohar, Oman.

\section{MATERIALS AND METHOD}

A cross-sectional questionnaire based study was conducted among the $3^{\text {rd }}$ year medical students of College of Medicine and Health Sciences, NUST, Sohar, Oman. Ethical clearance for the study protocol was obtained from the institutional research and ethics committee. A total of 120 third year MD medical students were included in this study. There were 108 (90\%) female students and $12(10 \%)$ male students. Their grades score was 3.5 and more, hence all students were comparable in terms of previous educational background.

The study participants were divided into two groups. The first group of sixty students was taught biochemistry topics using the black board whereas the second group of sixty students 
was taught the same topic using PowerPoint presentation. Both groups were taught by the same instructor and on the routine scheduled time and day (i.e., two days per week-totally four hours) on a weekly basis for eight weeks. The course instructor used the same textbook, tests, and lecture materials during the lectures.

Traditional lectures or "Chalk and talk" methods include writing on the black board using conventional methods via direct speech and using chalk and board in the classroom during regular course lectures. The majority of the material was verbally presented in the lecture. Graphs and figures were drawn on the chalkboard when illustrations were needed. There was no other equipment used for presentation except the instructor delivered the lecture using a microphone.

PowerPoint presentations were run on a Hitachi model CP-EX250 overhead projector. In order for the material to be legible, all lights were switched off in the room and the contrast setting on the projector was on the highest level. The presentation included 25 slides, among which 13 slides were diagrams and the remaining slides had written material related to the topic. Each slide had either one diagram or written material in six to eight lines with sufficient spacing between lines. Each letter was 2-3 inch in height and width. None of the slides had sound effects or diagrams/pictures not related to the topic. Students were not given any handouts regarding the topic but were allowed to write down notes from PowerPoint slides during the delivery of the lecture. The instructor delivered the lecture using a microphone. The instructor received no complaints from students about the legibility, audibility, or lighting in the room. To confirm this, two staff members were made to seat in the last row behind the students.

A predesigned and pretested questionnaire containing 12 questions were given to students at the end of the lecture. Informed consent form (in English and Arabic) was given to the students after explaining the purpose of the study. The participation in the study was on voluntary basis. The questionnaire was designed to compare the two delivery styles with regard to the experimental setting. A questionnaire was designed to assess the opinion of students regarding blackboard and PowerPoint presentation on Biochemistry topic. The questionnaire form was validated by five subject experts prior to the study. The study was conducted to the students who were exposed to various teaching aids earlier. Students were explained about objective of the present study and instructed to mark appropriate answer for each question in the questionnaire form. They were told to give their honest and sincere opinion regarding the best teaching aid they preferred.

\section{Grading:}

The above twelve parameters were analyzed on the basis of scale of grading. Strongly Agree (5), agree (4), neither agree nor disagree (3), disagree (2), strongly disagree (1). The sum of all 
the students' grading on each parameter was used to calculate the final weighted score. The overall preference of the students is estimated using the method of weighted average, for finding the weighted score of each parameter regarding the different lecture delivery methods. The students were also asked to write their comments on the lecture delivery methods. They were also interviewed further in the light of the analysis of questionnaire. These questions were pertaining to different aspects of lecture and overall satisfaction of the students with the method of lecture delivery. Students were supposed to choose one of the two methods for each aspect of the lecture, to know their preference for a particular type of teaching methodology. For each of these methods, the students were asked mark $(\boldsymbol{V})$ for their preferred method regarding following aspects of lecture delivery. Each aspect was carrying one mark.

\section{Data analysis:}

The data were collected and analyzed for statistical analysis by ANOVA tests using SPSS 20 version. $P$ values of $\leq 0.05$ were considered statistically significant. Descriptive Statistics in the form of mean and median with standard deviation and estimated standard error of mean was calculated. For inter-group comparison, between the values obtained from both group, student's t-test was applied. Results were expressed in percentages and showed through bar diagram and pie chart. The result was tabulated and each aspect of lecture and its delivery method was compared using the sum of the score obtained for each method. The above parameters were analyzed and the overall preference of the students is assessed after compilation of these parameters by summing up the marks for each method. Student's preference of a particular methodology for any particular aspect of lecture was also analyzed.

\section{RESULTS AND DISCUSSION}

A total of 120 third year MD medical students filled up voluntarily the study questionnaire. The majority of surveyed students were in favor of the PowerPoint lectures which had superior clarity and were more understandable. This approach stimulates their interest and provokes their understanding of the subject. The lectures were well organized, clearer with respect to terminology, spellings, pronunciation, clarity of diagrams, better visibility and have the continuity of lecture contents. The majority of the students rated PowerPoint teaching higher in terms of all the parameters studied especially the overall effectiveness and students, satisfaction, as compared to the chalkboard except the ability to take notes more easily and the chalk and board method was more interactive (Graph 1). 


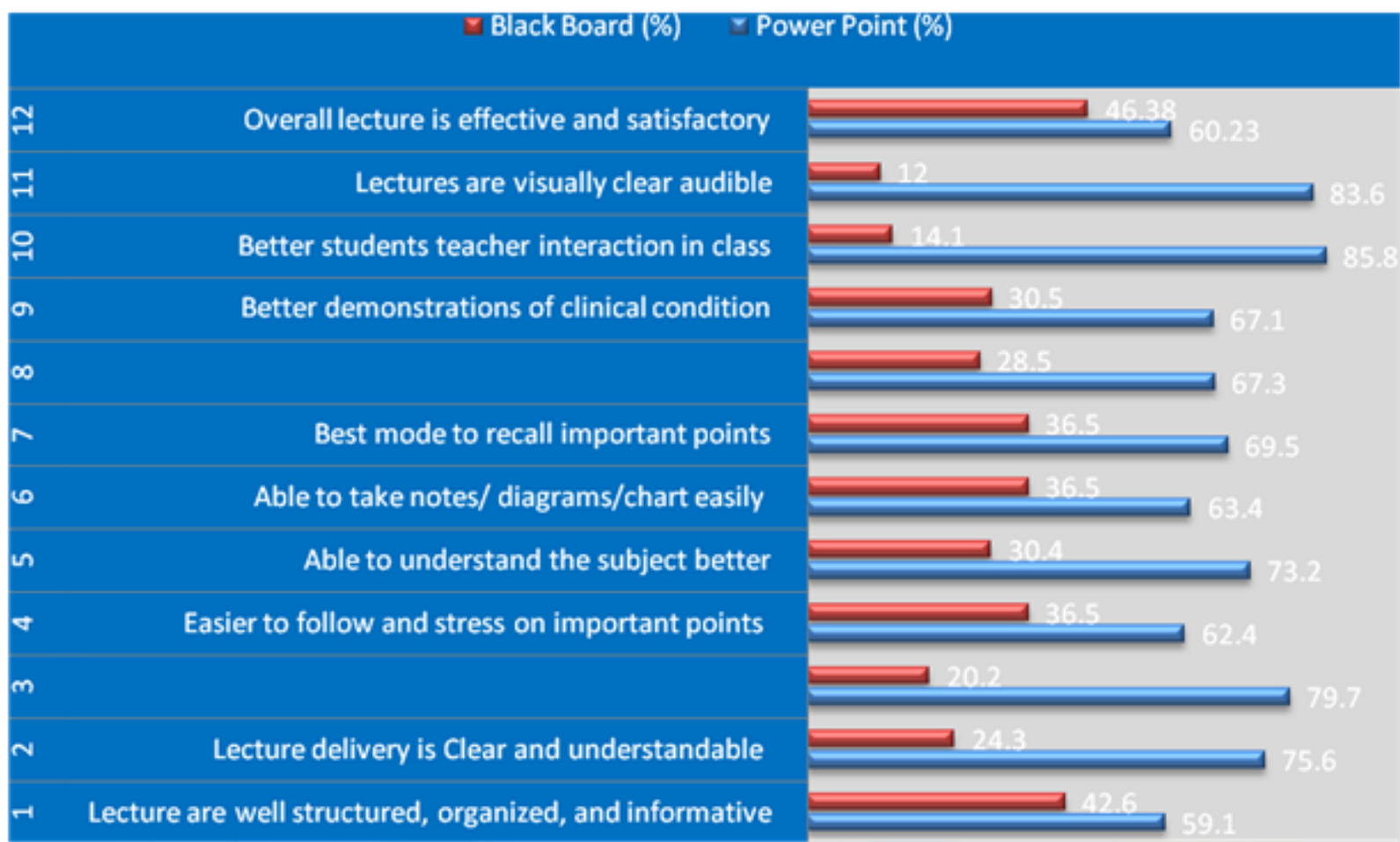

\section{Graph 1: Percentage distribution of parameters in PowerPoint \& Blackboard teaching} methods

The students' overall preferences for each the lecture delivery method was $73(60.23 \%)$ out of 120 students preferred PowerPoint for overall effectiveness and satisfaction of the lecture delivery method \& $47(46.38 \%)$ students preferred blackboard method for delivery of lecture (Figure 1).

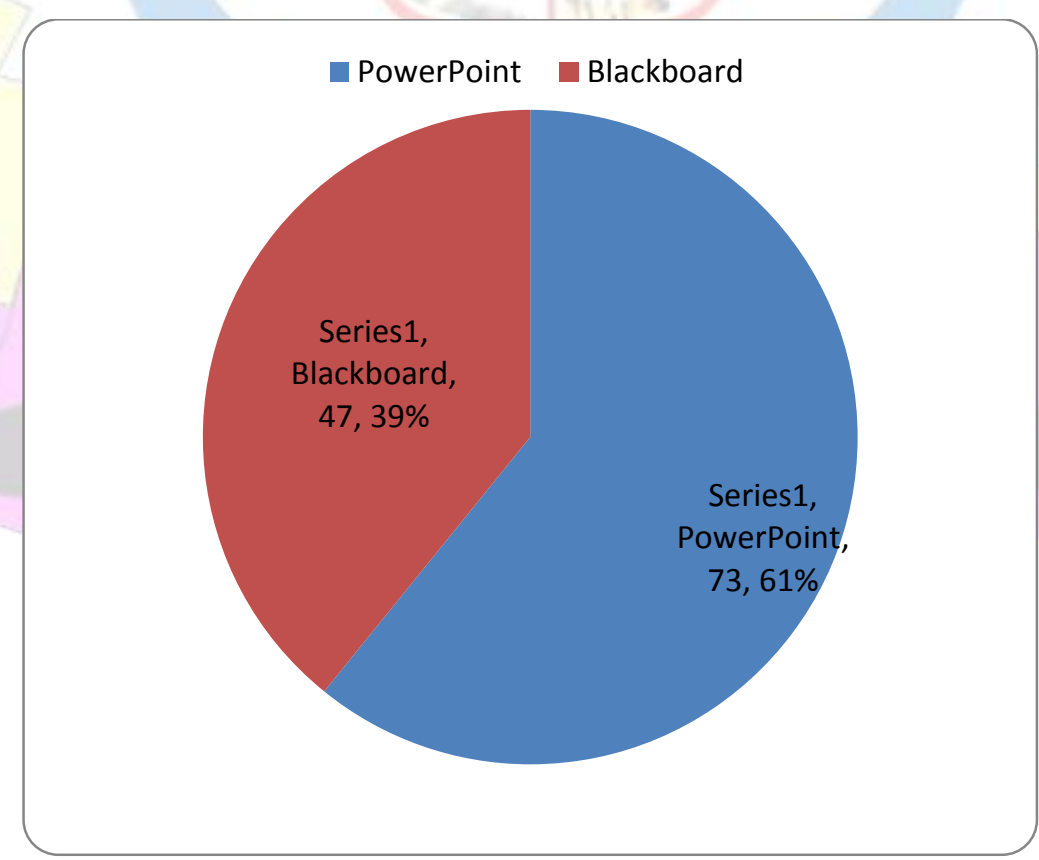

Figure 1: Pie diagram showing overall preference of students between blackboard and PowerPoint teaching methods 
Also more subject coverage and demonstrations of clinical conditions were comparatively better in PowerPoint teaching method. Whereas average scores given by the students to lectures using blackboard were 21.40, and using PowerPoint were 24.21 out of a maximum score of 25 . The difference among the assessment scores of lectures using blackboard, and PowerPoint was statistically highly significant $(\mathrm{P}$ value $<0.001)$.

Several students commented that the effectiveness of the PowerPoint presentations lecture was that they avoid the issue of poor handwriting and dirty blackboard. It is more interesting and engaging. Use of various animation and other properties of PowerPoint can make lectures more interesting for students. Hence it becomes more eyes catching. Voice of every teacher may not reach effectively/audible to all the students with blackboard teaching, hence visualization along with lecture can be more effective and will help to expand the teaching methodology in PowerPoint teaching. Several students commented the main reason for disliking PowerPoint presentations was the presentation contained too much material. The lectures were delivered too fast. With PowerPoint method the students may become a passive observer rather than an active participant. Also PowerPoint system can get adversely affected especially in developing countries where factors such as limited infrastructure and an irregular power supply need to be taken into account.

Few students had also commented main reasons for liking traditional lectures using blackboard was the lectures contained natural pauses and breaks (e. g. during writing or rubbing the blackboard) allowing students to follow the material. Also it avoids the issue of power failure leading to interruption of the lecture. While the main reasons for disliking were that many times the blackboard was dirty or the chalk was faulty and sometimes the handwriting was not legible. Also it took more time to present the same information as compared to the electronic presentations.

Learning and teaching are continuous processes which act simultaneously. This can be demonstrated when learners acquire the ability to express their gained insight, realization, facts, and new skills. A good teaching needs a good communication for exchanging ideas and information. It is a complex process and has five main components viz. Source (teacher), Receiver (audience/ students), Message (content/lecture), Channels (medium / traditional blackboard, OHP, and PowerPoint), and Feedback (effect) ${ }^{2,5}$.

The major limitation of lectures is that listener passively receives the material and feels bored and sleepy. Lectures can be made more effective by using visual aids. PowerPoint is most commonly used visual aid. Handouts are given out in advance in PowerPoint teaching, so the students tend to focus more intently on the lectures. Hence, a good lecturer can motivate the students on a journey of discovery, exposing students to one interesting fact after another by 
PowerPoint teaching method. Students will have better retention of the subject afterward if the notes are written with the lecturer's explanation ${ }^{6}$.

In traditional blackboard teaching, the conventional lecture method commonly involves the use of black or white board with chalk or marker and has the advantage of being cheap/ economical. However, the disadvantage is, it may cause notes taking as a tiring \& fatigue task, especially after continuous and long lectures. In blackboard teaching, it could be difficult to the student to catch pace/ continuity with the lecturer if student lose focus for even a moment ${ }^{7}$.

In PowerPoint teaching the lecturer prepares photographic slides and distributes the same to the students before the lecture. The lecturer shows the PowerPoint slides and explains the important points during the lectures. PowerPoint promotes better organization and understanding of the lecture topics as the coverage and flow of subject are well fixed within a finite number of slides (Graph 1). During lecture, the individual PowerPoint slides serve as memory aids, which reduce the mental strain on the lecturers. As most of the contents are already given in the form of handouts, this reduces the need to take notes during the lecture and students find this PowerPoint method less tiring. Moreover, students able to pay more attention to the discussion part of the topic instead of taking notes. The handouts are also more portable and distributed as softcopies rather than printed copies. Students can easily view these softcopies on any electronic device such as personal computer, laptop or even in mobile phone. PowerPoint slides can be reused or can be edited with ease for future lessons; this makes lectures to prefer this aid.

Present study has shown that PowerPoint teaching is most preferred teaching aid by our students $(60.43 \%)$ when compared to black board teaching method (39.56\%) (Figure 1). In PowerPoint teaching, the students are active participants and are able to cope with the teaching speed of the teacher. It also motivates an interest in students and helps in holding attention in the class ${ }^{3}$.

In this study, students preferred PowerPoint because it improves interaction between students and teachers. $81.6 \%$ felt that flow of thought is better, $77.5 \%$ students reported that PowerPoint stimulate interest, and $71.4 \%$ of students observed better understanding of topic, and $73.4 \%$ of students felt that PowerPoint teaching had improves their problem solving potential (Table 1). 
Table 1: Students opinion for PowerPoint and Blackboard teaching method

\begin{tabular}{llll}
\hline S.No. & Parameters & PowerPoint(\%) & Blackboard (\%) \\
\hline 1 & $\begin{array}{l}\text { Lecture are well structured, organized, and } \\
\text { informative }\end{array}$ & 59.1 & 42.6 \\
2 & Lecture delivery is Clear and understandable & 75.6 & 24.3 \\
3 & $\begin{array}{l}\text { Lecture hold my attention and Stimulate } \\
\text { interest and thinking }\end{array}$ & 79.7 & 20.2 \\
4 & Easier to follow and stress on important points & 62.4 & 36.5 \\
5 & Able to understand the subject better & 73.2 & 30.4 \\
6 & Able to take notes/ diagrams/chart easily & 63.4 & 36.5 \\
7 & Best mode to recall important points & 69.5 & 36.5 \\
8 & Covers more topics per lecture and better & 67.3 & 28.5 \\
& summarization & & \\
9 & Better demonstrations of clinical condition & 67.1 & 30.5 \\
10 & Better students teacher interaction in class & 85.8 & 14.1 \\
11 & Lectures are visually clear audible & 83.6 & 12 \\
12 & Overall lecture is effective and satisfactory & 60.23 & 46.38 \\
\hline
\end{tabular}

Our study result is comparable to the previous studies by Banerjee et al., and Novelli and Fernandes ${ }^{8-9}$. Nigerian study done by Hassan et al. reported that the PowerPoint presentations significantly improve the academic performance of medical students more than conventional lecture methods ${ }^{10}$. Vikas et al. also reported in Indian study that PowerPoint presentations are the most preferred instructional aid over the chalk-and-talk (black board) method among medical teachers ${ }^{11}$. Evans, findings appear to be promising because they suggest that lectures delivered in electronic format using the PowerPoint software will increase students' grades, improve lecture attendance rates, and may reduce certain disruptive behaviors during the lectures ${ }^{12}$.

Harknett and Cobane reported $80 \%$ percent of the students surveyed by the authors felt that PowerPoint lectures benefited their learning. Some felt that the visual emphasis in PowerPoint helped them recall the lecture material at the time of examination ${ }^{13}$. Mayer and Anderson RB (1992) pointed out that in PowerPoint the ability to integrate text, pictures, and images is a great advantage which improves the educative value of the subject ${ }^{14}$.

Some authors have observed that PowerPoint presentations encourage an active learning environment, increase the effectiveness of lectures, and lend clarity to the subject ${ }^{15-17}$. Some authors commented that PowerPoint presentations was well organized and well structured (contain texts, pictures, animation, voices, and video), they can provide an interactive environment for the active engagement of students, thereby motivating them to attend lectures when presentation graphics are used compared with blackboard (chalk-and-talk) presentations ${ }^{18-20}$. Therefore, students can learn better or retain the material from class more. 
In this study, $60.38 \%$ of students preferred PowerPoint teaching method (Figure 1). The reason for this may be due to PowerPoint ability to enhance the learning process and invoking students' interest in addition to explanation of complex illustrations. The limitation of the current study is due to small sample size based on the results of a single batch of $3^{\text {rd }}$ year medical students only. However, a metacentric study with high sample size would be beneficial to assess the best teaching aids in medical education.

\section{CONCLUSION}

The effectiveness of the lecture depends upon the teacher, regardless of the teaching aid used. Present study reflects the views of students regarding more use of multimedia in teaching medical subject. Majority of students preferred PowerPoint as the mode of lecture delivery. Similar finding were also reported in various previous studies as well. In our study which compared the traditional and conventional chalk and board method with PowerPoint presentation, significant majority of students clearly preferred use of PowerPoint presentations over conventional chalk and board method for delivering lectures. Therefore, the present studies support the superiority of PowerPoint presentation as lecture delivery method over the traditional chalk and board method.

\section{STUDY LIMITATION}

This study is conducted in one medical college so the result cannot be generalized. Further research is required at different medical colleges at different level in a larger sample size.

\section{DISCLOSURE STATEMENT}

Authors declared no conflict of interest and no funding was received for this work.

\section{ACKNOWLEDGEMENT}

We acknowledge and are thankful for the support provided by the College of Medicine and Health Science, National University of Science and Technology, Sultanate of Oman.

\section{REFERENCES}

1. Squires G. A frame work of teaching. Br J Educ Stud. 2004;52:342-358.

2. FalkNilsson E, Walmsley D, Brennan M, Fournier DM, Junfin Glass B, Haden K, et al. 1.2 Cognition and learning. Eur J Dent Educ. 2002;3:27-32.

3. Baxi SN, Shah CJ, Parmar RD, Parmar D, Tripathi CB. Students perception towards different teaching aids in a medical college. Afr J Health Prof Educ. 2009;1:15-16.

4. Prasad S, Roy B, Smith M. The art and science of presentation: Electronic presentations. J Postgrad Med. 2000;46:193-198.

5. Chadwick SM, Bearn DR, Jack AC, O’Brien KD. Orthodontic undergraduate education: Developments in a modern curriculum. Eur J Dent Educ. 2002;6:57-63. 
6. Golden AS. Lecture skills in medical education. Indian J Pediatr. 1989;56:29-34.

7. Saalu LC, Abraham AA, Aina WO. Quantitative evaluation of third year medical students' perception and satisfaction from problem based learning in anatomy: A pilot study of the introduction of problem based learning into the traditional didactic medical curriculum in Nigeria. Educ Res Rev. 2010;5:193-200.

8. Banerjee I, Jauhari AC, Bista D, Johorey AC, Roy B, Sathian B. Medical students view about the integrated MBBS course: A questionnaire based cross-sectional survey from a medical college of Kathmandu Valley. Nepal J Epidemiol. 2011;1:95-100.

9. Novelli ELB, Fernandes AAH. Students' preferred teaching techniques for biochemistry in biomedicine and medicine courses. Biochem Mol Biol Educ. 2007;35:263-266.

10. Abdulaziz H, Isa U, Sani A. Impact of Power-Point Presentation on the Academic Performance of Medical Students of Ahmadu Bello University Zaria. Sub-Saharan African Journal of Medicine. 2014;2:3-7.

11. Vikas S, Prerna U, Mushtaq A, Virendra K. An assessment of teachers' preference for lecture delivery methods in medical education. Educ Res Rev. 2010;5:533-537.

12. Evans, L. (1998). Preliminary study: lectures versus PowerPoint. 4.0 http://www.kcmetro.cc.mo.us/longview/lect_ppt.HTM.

13. Harknett RJ, Cobane CT. Introducing instructional technology to international relations. Political Science and Politics. 1997;30:496-500.

14. Mayer RE, Anderson RB. The instructive animation: Helping students build connections between words and pictures in multimedia learning. J Educ Psych. 1992;84:444-452.

15. Hunt N. Enhancing lectures the modern way. The New Academic. 1998:3-9.

16. Sammons MC. Using PowerPoint presentations in writing classes. The Technology Source. 1997.

17. Rossen S, McGraw D, Graham E, Lee D. "Enhancing your lecture with presentation software-Setting instructional goals". 1997 Last updated September 1997 by David McGraw for Faculty New Media Center (FNMC) at UCLA Office of Instructional Development. Available from: http://www.oid.ucla.edu Accessed June 10, 2010.

18. Glomonarzoles DT. The effect of multi-media instruction on student clearning. J Educ Pract.2013;4:126-131.

19. Madhavaiah G, Nagaraju C, Peter S. Innovative methods in teaching English Language and communication skills. Int J Sci Res Rev. 2013;2:141-145. 
20. Qazi F, Shoaib MH, Yousuf RI, Zafar S, Bano N. Pharmacy students' perceptions of learning experience with traditional and power point presentations. World J Educ Technol. 2014;6:27-36.

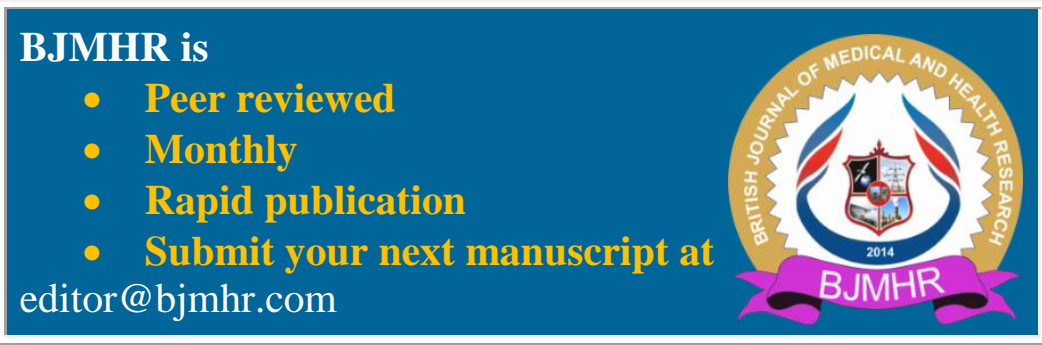

